\title{
Long chain fatty acids: in vitro cholecystokinin production and in vivo energy intake and body composition alteration
}

\author{
C. J. Harden ${ }^{1,2,3}$, A. N. Jones ${ }^{1}$, T. Maya-Jimenez ${ }^{1}$, M. E. Barker ${ }^{1}$, N. J. Hepburn ${ }^{4}$, I. Garaiova ${ }^{4}$, \\ S. F. Plummer ${ }^{2}$ and B. M. Corfe ${ }^{1}$ \\ ${ }^{1}$ Department of Oncology, School of Medicine and Biomedical Sciences, The University of Sheffield, Sheffield, S10 2RX, \\ ${ }^{2}$ Cultech Ltd, Unit 3, Christchurch Road, Port Talbot, West Glamorgan, SA12 7BZ, ${ }^{3}$ Centre for Food Innovation, \\ Sheffield Hallam University, Sheffield, S1 IWB and ${ }^{4}$ Obsidian Research Ltd, Unit 2, Christchurch Road, Port Talbot, \\ West Glamorgan, SA12 7BZ
}

Long chain fatty acids may suppress appetite and reduce energy intake by stimulating release of gastrointestinal hormones such as cholecystokinin $(\mathrm{CCK})^{(1)}$. Their differential effect on CCK release, energy intake, body weight and body composition is not comprehensively understood ${ }^{(2-5)}$.

An in vitro screen using STC-1 cells was used to assess the effects of NEFA on CCK production. CCK concentrations were determined by ELISA. The order of fatty acid induced CCK release per $\mu \mathrm{g}$ cellular protein was docosahexaenoic $(3.08 \mathrm{ng} / \mu \mathrm{g})$, eicosapentaenoic $(2.26 \mathrm{ng} / \mu \mathrm{g})$, pinolenic $(1.61 \mathrm{ng} / \mu \mathrm{g})$, linoleic $(1.44 \mathrm{ng} / \mu \mathrm{g})$, oleic $(1.39 \mathrm{ng} / \mu \mathrm{g})$, conjugated linoleic $(1.32 \mathrm{ng} / \mu \mathrm{g}), \mathrm{lauric}(1.17 \mathrm{ng} / \mu \mathrm{g})$ and ethanol $(1.16 \mathrm{ng} / \mu \mathrm{g})$. DHA stimulated significantly more CCK production than the other NEFA tested $(P<0.01)$. An acute randomised, controlled, crossover intervention using healthy males $(n-18)$ compared the effect of consuming an emulsified preload containing DHA, oleic acid (OA) or no-treatment on food intake over a $24 \mathrm{~h}$ period. Subjects consumed $12097 \mathrm{~kJ}$ after no treatment, $9912 \mathrm{~kJ}$ after OA and $8539 \mathrm{~kJ}$ after DHA. There was significantly lower energy intake following DHA relative to no treatment $(P=0.039)$, which was not matched by OA. In a double-blind, randomised, controlled study of the DHA and OA containing emulsions, overweight female ( $n$ 40) subjects consumed twice $6 \mathrm{ml}$ daily dose of either emulsions for 12 weeks. At the end of the intervention, mean body weight (kg) was reduced by $3.5 \%$ in the DHA group and by $1.1 \%$ in the OA group. BMI $\left(\mathrm{kg} / \mathrm{m}^{2}\right)$ was reduced by $3.9 \%$ in the DHA group and by $1.9 \%$ in the OA group. Mean body weight and BMI were significantly reduced for the DHA group compared with the OA group $(P=0.037$ and 0.032 , respectively).

DHA is a stimulant of CCK in STC-1 cells. In two distinct human feeding studies, DHA consumption significantly reduced total daily energy intake and reduced body weight and BMI.

1. Pasman WJ, Heimerikx J, Rubingh CM et al. (2008). Lipids Health Dis 7, 10.

2. Li JJ, Huang CJ \& Xie D (2008) Mol Nutr Food Res 52, 631-645.

3. Buckley JD \& Howe PR (2009) Obes Rev 10,648-659.

4. Hand KV, Bruen CM, O'Halloran F et al. (2010) Mol Nutr Food Res 54, 93-103.

5. Parra D, Ramel A, Bandarra N et al. (2008). Appetite 51, 676-680. 